keen interest and skill in spectroscopy and interferometry. As a result of his research on "An Oscillating Fabry-Perot Interferometer" he took his Ph.D. degree. In 1960 he was appointed lecturer in physics in the Section of Applied Physics at the Imperial College of Science and Technology, where he extended his research interest into photoelectronics and space research. Then in 1964 he returned to the Royal Holloway College as reader in physics from where, after only two years, he will transfer to the chair of physics at Belfast. Thus, Dr. Bradley's career began in school teaching and he came into academic physics the hard way. However, this may partly be responsible for his great success as a teacher. Though beginning rather late in university teaching and research in physies, his enthusiasm and ability have carried him a very long way in a short time. $\mathrm{He}$ is a very skilful experimenter with a genial nature that engages the confidence of both undergraduate and postgraduate students and makes him a very congenial colleague. All who have known him will feel confident that he will be very successful in his new post.

\section{Low-energy Electron Diffraction}

ONE of the first demonstrations in Britain of the technique of low-energy diffraction was recently provided at the Sunbury Research Centre of the British Petroleum Company by Dr. R. Szostak of the Fritz Haber Institute, West Berlin. The technique is being used at a number of laboratories for the study of the structure of the few layers near the surface of a solid crystal which can be penetrated by a beam of electrons with an energy of the order of a hundred volts or less. Dr. Szostak's lecture and demonstration were concerned with the application of the technique to whiskers of iron. Dr. Szostak emphasized that iron is a difficult specimen for single crystal studies because of its $\alpha \rightarrow \gamma$ transition near $900^{\circ} \mathrm{C}$ and because of impuritios, both inherent and induced by cutting and orientating, in massive single erystals. He has found, however, that naturally grown and well-established side faces of whiskers, formed by the reduction of iron (II) chloride in hydrogen near $800^{\circ} \mathrm{C}$, offer a successful specimen. Faces exhibited have $(100)$ and $(110)$ orientation. Very bright diffraction patterns were achieved from targets only $0.01 \mathrm{in}$. broad and with beam energies as low as 5 electron-volts.

After heating up to $850^{\circ} \mathrm{C}$ the $(100)$ faces exhibited a structure similar to the well-known domain structure of ordered alloys. The pattern expected from clean iron (100) surface was also observed after a long period of ion bombardment and annealing, but this interpretation should be treated with some caution. The addition of oxygen to this surface led to ordered oxide structures with a poriodicity equal to a small integral multiple of the unit cell dimensions.

The (110) faces exhibited a great variety of more complicated super-structures and a 'clean' surface could not be obtained without a high background intensity.

Dr. Szostak said that his study of this system was only a preliminary, and that future work would involve more detailed investigation of specific aspects of these interactions.

\section{Advances in Fluorine Chemistry}

VouUme 5 of Advances in Fluorine Chemistry covers only two broad topics: oxyfluorides of nitrogen and fuorides of phosphorus (edited by Prof. M. Stacey, Prof. J. C. Tatlow and Dr. A. G. Sharpe. Pp. 288. London: Butterworth and Co. (Publishers), Ltd., 1965. 75s.). The first topic is a thorough review of the preparations, reactions and properties of nitrosyl fluoride, nitryl fluoride, and nitroxy fluoride or fluorine nitrate. The thirty pages and 135 references cover a period from 1905 to 1963. The author of the chapter is Dr. C. Woolf, of the Allied Chemical Corporation. The presentation and format follow closely the tradition established by other contributors to prior volumes of this series. The second topic is by Dr. R. Schmutzler, of the E. I. du Pont and de Nemours Company, and is a monumental coverage of almost every known compound which has at least one fluorine atom bonded to phosphorus. The chapter covers more than 230 pages of text involving 771 references in the field. There are more than sixty tables of data which help to bring the topical material into sharp focus for the reader, and apparently no figurative stone has been left unturned to cover the available information and present it in Teutonic detail. Among the topies treated are trivalent and pentavalent phosphorus fluorides, mixed halides, oxyhalides and thiohalides; fluorophosphanes, fluorides of phosphinic and phosphonic acids and their ester and amide derivatives; the fluoroacids of phosphorus and the fluorophosphazenes. 'There is also a very important section on infra-red, and fluoride-19 and phosphorus-31 nuclear magnetic resonance spectroscopy with chemical shift and coupling constant data made available for literally hundreds of chemical species. Considerable emphasis has been paid to fluorophosphorus compounds as co-ordinating ligands in complexes so that this chapter, which is probably the most thorough one in the series, will also be of interest to co-ordination chemists as well as organic and inorganic fluorine chemists.

\section{More Technical Training}

SUGGESTIONS for making fuller use of technical colleges in Britain have been put forward to the Secretary of State for Education and Seience by the Committee on Technical Resources-a sub-committee of the National Advisory Council on Education for Industry and Commerce. The recommendations have been warmly welcomed by the Minister, who promises vigorous action in pursuit of a number of detailed recommendations. Clearly the British Government has been overjoyed-and perhaps even surprised-to be told that at least one part of the educational system must be thought of as containing "a very considerable reserve of resources".

According to the statistics in the report of the committee, roughly $1,700,000$ students - some full-time and some part-time- now attend technical colleges and other establishments of further education. Investment in these institutions since the Second World War exceeds $£ 200$ millions. More recently, the pace of growth, in buildings and in numbers of students, has been particularly quick, and the committee looks forward to even faster growth once the full impact is felt of the work of the industrial training boards now being established, and which are intended to ensure uniform standards of technical training. The same development may well make more funds available to the technical colleges.

The committee's confidence that productivity can be dramatically increased in this frequently neglected part of the educational system rests on its discovery that the sizes of classes now being taught in technical colleges and other institutes of further education are frequently much smaller than they need to be. Among some 86,000 classes of all kinds, the committee found that no fewer than 63,500 were constituted of between eleven and fifteen students. These figures compare favourably with the sizes of senior classes in secondary schools, where the character of the teaching is often very similar. In the circumstances, not even teachers in technical colleges will be surprised that the committee recommends a less generous ratio of staff to students, and a fuller use of educational plant thereby. It is less easy to understand that much of the difficulty about using technical colleges to the full should apparently stem from a misinterpretation of a government policy first laid down in 1957, and which was intended to ensure that public funds could not be spent on technical college courses unless fifteen studenta enrolled in the first year. Frequently, it seems, this 